\title{
LAS COMPAÑÍAS BANCARIAS GENOVESAS EN MADRID A COMIENZOS DEL SIGLO XVII
}

por

\section{CARLOS ÁlVAREZ NOGAL}

Universidad Carlos III de Madrid

RESUMEN: Las empresas bancarias genovesas que dominaron las finanzas castellanas entre 1600 y 1640 tenian una serie de características comunes que merecen ser estudiadas. Tanto su organización, menos dependiente de la familia de lo que tradicionalmente se ha sostenido, como el tipo de estrategia utilizada para desarrollar sus negocios, fueron elementos esenciales de su éxito. A pesar de lo que los contemporáneos acusaron a los genoveses de recibir un trato privilegiado por parte de la corona española, o de ser verdaderos monopolios, lo cierto es que estas compañias supieron generar confianza, ser competitivas y gestionar con gran eficacia toda la información que exigía su actividad financiera. La organización de estas empresas en forma de red, ofreciendo a sus agentes gran autonomía, explica en parte su superioridad, pero también resultó ser su mayor debilidad a largo plazo.

Palabras Clave: Banqueros. Crédito. Sistema financiero de Castilla. Historia económica. Siglo XVII.

ABSTRACT: Many Genoese banking companies worked in Castile between 1600 and 1640. All of them bad common features that deserve to be studied. The organization of these companies and their strategies for developing their commercial and financial businesses were both essential elements in their success. Although many contemporaries accused the Genoese bankers of receiving privileges from the Spanish Monarchy, or behaving as monopolies, the truth is that these companies were very competitive. The organization of these companies in networks, offering their agents a great autonomy, explains their success in Castile for decades, but in the long term it was also their weakness.

KEY WORDS: Bankers. Credit. Castilian Financial System. Economic history. XVII Century.

Hispania, LXV/1, núm. 219 (2005) 67-90 
La presencia genovesa en Castilla fue una constante desde el final de la Edad Media ${ }^{1}$. Su creciente especialización en la provisión de servicios financieros en los siglos XVI y XVII, permitió que algunos llegasen al gobierno de la Monarquía formando parte de sus Consejos. Sin duda, el final del reinado de Felipe II y la década de 1640 fueron una fase de esplendor para la comunidad genovesa, especialmente en Madrid, tanto por el volumen de sus operaciones, como por la estabilidad de sus empresas.

Sus contactos internacionales en distintas plazas europeas les proporcionaban el crédito y la información que necesitaban para ofrecer en la península Ibérica el tipo de servicios financieros que demandaban tanto la Corona española, como el sector privado ${ }^{2}$. A pesar de su relevante papel de intermediación y de su importante contribución al desarrollo de la economía de Castilla, apenas se han realizado estudios sobre el funcionamiento y la organización de sus empresas $^{3}$. Se conoce a estos banqueros por ser los suministradores del crédito que hacían posible la política imperial de la Monarquía, pero nada se sabe del resto

1 OTTE, Enrique: «Il ruelo dei genovesi nella Spagna del XV e XVI secolo», en Aldo de MAdDAlena e Hermann KellenbenZ: La Republica internazionale del denaro tra XV e XVII secolo, Bologna, 1986, pp. 17-56. GonZÁlez Gallego, I.: «El libro de los Privilegios de la nación genovesa», Historia, Instituciones, Documentos, I, 1974, pp. 275-358.

2 Felloni, G.: «Asientos, juros y ferias de cambio desde el observatorio genovés (1541-1675), en Otazu, A.: (ed.). Dinero y Crédito (siglos XVI al XIX). Madrid, 1978, pp. 335-359. DoriA, G.: «Conoscenza del mercato e sistema informativo; il know-how dei mercanti finanzieri genovesi, nei secoli XVI e XVII", en Aldo de MADDALENA e Hermann KellenBENZ: La Repubblica internazionale del denaro tra XV e XVII secolo, Bologna, 1986, pp. 57-122.

3 La falta de estudios sobre el funcionamiento del sistema financiero castellano no se limita sólo al funcionamiento de las empresas bancarias genovesas. Gracias a Hamilton y Ruiz Martín, sabemos de la existencia de éstas y otras instituciones, HAMILTON, E.J.: «Spanish Banking Schemes before 1700", Journal of Political Economy, LVII, 1949, pp. 134-156. RUIz MARTíN, F.: «La banca en España hasta 1782", en VV.AA. El Banco de España. Una bistoria económica, Madrid, 1970, pp. 1196., pero apenas nada sobre su funcionamiento. Es necesario explicar mejor qué eran los bancos de Corte, las actividades que tenían encomendadas, las normas que los regulaban, cómo estaban organizados y por qué desaparecieron a principios del siglo XVII, TINOCO RUBIALES, S.: «Rey, ciudad, crédito: iniciativas y restablecimiento de los bancos públicos en Sevilla, 1578-1582», en BERNAL, A.M. (ed.): Dinero, moneda y crédito, Madrid, 2000, pp. 695-703. Carecemos de estudios, salvo informaciones puntuales, sobre la función de los depositarios generales en las principales ciudades del reino. Existe información sobre la evolución de las ferias castellanas, ESPEJO, C. y PAZ, J.: Las antiguas ferias de Medina del Campo, Valladolid, 1908, BASAS FERNÁNDEZ, M.: «Relaciones económicas de Burgos con Medina del Campo en el siglo XVI", en Lorenzo SANZ, E.: (coord.): Historia de Medina del Campo y su tierra, vol. II, pp. 437-481, pero no sobre el papel jugado en ellas por los mercaderes de ámbito internacional y su final desplazamiento a Madrid, según apunta Ruiz MARTín, F.: «El Consulado de Burgos y las ferias de pagos de Castilla», Actas del V Centenario del Consulado de Burgos, vol. I, Burgos, pp. 623-638; del papel jugado por las diputaciones para el consumo de vellón como instituciones financieras, DUBET, A.: Hacienda, arbitrismo y negociación política: el proyecto de los erarios públicos y Montes de Piedad en los siglos XVI y XVII. Valladolid, 2003 que inicialmente nacieron unidas al proyecto de erarios, pero que después funcionaron de forma independiente.

Hispania, LXV/1, núm. 219 (2005) 67-90 
de sus actividades en España ${ }^{4}$ ¿Quiénes eran esos mercaderes-banqueros? ¿Cómo trabajaban? ¿Cómo resolvían los problemas de información de sus compañías? ¿Qué mecanismos utilizaban para generar confianza en los acuerdos que establecían con sus clientes y colaboradores? Son algunas de las muchas preguntas que aún es necesario responder.

El hecho de que la Corona fuese uno de sus principales clientes no impidió que la estructura organizativa de sus negocios, tanto en Castilla, como en el resto de Europa, obedeciese a criterios privados y de eficacia. Precisamente, una de las claves de su éxito parece haber sido su capacidad para competir. Prueba de ello es el reducido número de quiebras que sufrieron sus representantes más destacados ${ }^{5}$. Se trataba de financieros de ámbito internacional cuyas pautas de trabajo y colaboración abarcaban todo el continente europeo. Las oportunidades de negocio que existían entonces en la península Ibérica impulsaron a las mejores y más importantes empresas bancarias del continente a establecerse en Madrid.

La existencia de un sector financiero desarrollado y eficiente en la península era esencial para su desarrollo económico. España tuvo la fortuna de contar desde muy pronto con él, como lo demuestra la existencia desde la Edad Media de instituciones e instrumentos de crédito de rango internacional. En las regiones económicamente más desarrolladas de Europa como Castilla, circularon letras de cambio libradas por entidades públicas y privadas que ofrecían crédito a particulares, admitían depósitos, concedían hipotecas, gestionaban la compra-venta de deuda pública, seguros, etc. Aparecieron los corredores en distintos ámbitos de intermediación; se desarrollaron prácticas contables cada vez más precisas ${ }^{6}$; y surgieron instituciones como las ferias, que impulsaron el comercio y las finanzas.

4 La mayoría de la bibliografía sobre los banqueros genoveses en España está ligada a la investigación sobre la Real Hacienda, las finanzas imperiales, la negociación del crédito con el Consejo de Hacienda y su participación en asientos. CARANDE, R. Carlos V y sus banqueros, Madrid, 1965-67. UlloA, M.: La Hacienda Real de Castilla en el reinado de Felipe II, Roma, 1963. DOMínguez ORTIZ, A.: Politica y Hacienda de Felipe IV, Madrid, 1983. NER, E.: Uomini d'affari e di governo tra Genova e Madrid (secoli XVI e XVII), Milano, 1989. RuIz MARTín, Felipe: Las Finanzas de la Monarquía Hispánica en tiempos de Felipe IV (1621-1665), Madrid, 1990. ÁLVAREZ NOGAL, C.: El crédito de la Monarquía Hispánica durante el reinado de Felipe IV, Ávila, 1997. Álvarez NOGAL, C.: Los banqueros de Felipe IV y los metales preciosos americanos (1621-1665). Madrid, 1997. SANZ AYAN, C.: Los banqueros de Carlos II, Valladolid, 1988.

5 RUiz MARTin, F.: «La banca en España hasta 1782», en VV.AA. El Banco de España. Una bistoria económica, Madrid, 1970, p. 45. Ruiz Martín señala que tras las suspensiones de pagos de la Corona entre 1596 y 1607, los genoveses fueron capaces de desviar las pérdidas sobre otros, saliendo ellos impunes. ¿Por qué esa estrategia no fue utilizada por el resto de financieros? Quizá era una señal clara de su superioridad.

6 GoNZÁlEz FERRANDO, J.M.: «Los «libros de cuentas» de la Familia Ruiz, mercaderesbanqueros de Medina del Campo (1551-1606)» en Actas del Primer Congreso sobre Archivos Económicos de Entidades Privadas, Madrid, 1983, pp. 23-45.

Hispania, LXV/1, núm. 219 (2005) 67-90 
Además de estos instrumentos, Castilla también contó con agentes capaces de utilizarlos de forma eficaz. Los genoveses no fueron los únicos. Alemanes, milaneses, florentinos, portugueses, españoles, e incluso ingleses, participaron en negocios financieros como intermediarios y negociaron, en ocasiones, con la Corona. Sin embargo, los genoveses dominaron todo el sistema, tanto por su número, como por el volumen de sus negocios.

El objetivo de estas páginas consiste en aportar información sobre las características más destacadas de las empresas bancarias genovesas que actuaron en Castilla a principios del siglo XVII. Desvelar algunos datos sobre los inicios de su actividad, su estructura organizativa y su estrategia empresarial. ¿Es posible hablar de un estilo genovés de hacer negocios? La imposibilidad de abarcar a todos los agentes en tan breve espacio, nos ha obligado a concentrar el esfuerzo en los más representativos.

La documentación que hemos utilizado en esta investigación es fundamentalmente de carácter notarial. Por desgracia, no se conserva, o aún no ha sido encontrada en España, documentación privada de estas compañías de negocios. Por lo tanto, los libros de cuentas y la correspondencia de esos mercaderesbanqueros no están disponibles. Afortunadamente, la información que suministran los protocolos notariales de Madrid es lo suficientemente abundante y rica, como para intentar cubrir parte de esas carencias.

\section{UNA NUEVA GENERACIÓN DE BANQUEROS}

En torno a 1610 aparece en Madrid un grupo de banqueros genoveses que poco a poco ocuparon el centro de las finanzas castellanas y que acabaron sustituyendo a sus propios compatriotas. Este nuevo grupo controló hasta la década de 1640 la negociación del crédito de la Monarquía española y, especialmente, la exportación de metales preciosos. Los más destacados fueron Octavio Centurión, Carlos Strata, Juan Lucas Palavesín, Lelio Imbrea, Nicolo y Antonio Balbi, Francisco María Piquinoti, Bartolomé Spinola y Vicencio Squarzafigo ${ }^{7}$. No fueron ni los únicos genoveses, ni los únicos banqueros que sirvieron al rey, pero sí los que más dinero prestaron, y los que lo hicieron con mayor constancia. Otros muchos genoveses también intervinieron en los asientos del rey de España, pero en lugar de hacerlo negociando ellos directamente, prefirieron permanecer en un segundo plano, y participar de forma indirecta en los asientos que firmaba alguno de los citados.

Entre 1601 y 1606, este grupo de genoveses fundó compañías de negocios en la ciudad donde residía la Corte. Primero en Valladolid, durante seis años, y

7 Estos son sus nombres tal y como aparecen en la documentación española o se les conoce en España, en su relación con sus colaboradores italianos y en la documentación genovesa la trascripción de sus nombres es: Ottavio Centurione, Carlo Strata, Giovanni Luca Pallavicino, Lelio Invrea, Nicolo-Antonio Balbi, Francesco María Pichenotti, Bartolomeo Spinola y Vicenzio Squarciafico.

Hispania, LXV/1, núm. 219 (2005) 67-90 
después en Madrid, al recuperar la capitalidad. Ese grupo aparece en la mayor parte de los préstamos firmados por la Corona, o al menos en los de mayor volumen e importancia, y casi todos acabaron ocupando algún cargo de responsabilidad en el gobierno de la Monarquía o recibiendo un título nobiliario.

El grupo de genoveses que hasta entonces había negociado con la Corona fue desapareciendo poco a poco. Los más afectados por la bancarrota de 1596 prefirieron continuar en activo a través de las diputaciones que se crearon algunos años para negociar de forma conjunta con la Monarquía. Otros, menos perjudicados por la suspensión de pagos, continuaron al frente de sus negocios hasta el día de su muerte.

De la generación de banqueros genoveses establecidos en Madrid a finales del siglo XVI y sustituidos en la década de 1610 , destacan varios nombres. Uno de los más importantes fue Ambrosio Spinola, hijo de Francisco, que no debe ser confundido con el famoso general de Flandes a pesar de tener su mismo nombre y apellido. Al marqués de los Balbases, además de por sus servicios financieros, se le conoce por la célebre rendición de Breda que inmortalizó Velázquez. Otra importante compañía era la portuguesa «Esteban Lercaro y Julio Spinola». Esteban residía y trabajaba en Lisboa, mientras Julio lo hacía en Madrid, junto al rey de España. Julio también se apellidaba Spinola, pero no tenía ningún parentesco directo con los dos anteriores. Lo mismo ocurre con Joan Nicolao Spinola y con Agustín Spinola. Agustín llegó a tener un banco de Corte con sucursales en Madrid y Sevilla, a pesar de los impedimentos que existían para que los extranjeros pudiesen abrir este tipo de establecimientos. En el caso de Agustín, sí existían lazos económicos y familiares con Julio Spinola.

$\mathrm{Al}$ margen de este nutrido grupo de financieros con el apellido Spinola, también destacaron otros genoveses, entre los que se encontraban, sin pretender ser exhaustivos, «Juan Jacome y Domingo Doria», «Juan Bautista Judici y Melchor de Negrón compañía», Hector Picamillio, «Sinibaldo Fiesco y Juan Baustista Justiniano", "Marco Antonio de Negron y Teodoro Spinola, compañía», Lelio Diodati, "Juan Benito Spinola y Cattaneo Serra» y Agustín Raggio.

A la muerte de cada uno de ellos se liquidaron todos sus negocios y compañías. En la mayoría de los casos, fueron ellos los que pidieron en sus testamentos a otros financieros, amigos o colaboradores suyos, que pusieran en orden sus cuentas, llevasen a cabo su finiquito y velasen por el bienestar de sus herederos. Lo habitual fue que los negocios que hasta entonces habían tenido entre manos pasasen a otras compañías, y no que la compañía pasase a ser dirigida por otro hombre de negocios, ni por un familiar.

Tenemos dos significativos ejemplos. Ambrosio Spinola, hijo de Francisco, falleció en marzo-abril de 1615, heredándole su cuñado Jerónimo Doria y su hijo mayor Agustín. Ninguno de los dos mantuvo en activo su empresa, ni siquiera continuaron como banqueros con compañías privadas ${ }^{8}$. Julio Spinola

8 Archivo Histórico de Protocolos Notariales de Madrid (AHPNM), Protocolo 1380; f. 318. Testamento, 12/3/1615. 
había fallecido un año antes ${ }^{9}$. A pesar de la enorme actividad que desarrolló entre 1600 y 1614, su compañía fue liquidada por Nicolo Balbi y Juan Andrea Spinola, yernos suyos y dos de los hombres de negocios de la nueva generación. Ambos tenían sus propias compañías y competían desde hace años entre sí y con la de Julio. Ninguno de los hijos de Julio fue capaz de continuar con su casa de negocios, aunque tampoco su padre facilitó ese relevo.

\section{MADRID, CENTRO FINANCIERO INTERNACIONAL A PRINCIPIOS DEL SIGLO XVII}

La llegada de un nuevo grupo de banqueros entre 1600 y 1610 fue acompañada de un creciente protagonismo de Madrid como centro financiero castellano de rango internacional. Uno de los rasgos esenciales de todas las empresas genovesas que estudiamos aquí fue su estrecha vinculación con la capital de España, y su marcada voluntad de residir allí donde estuviese la Corte del rey. Esta importancia de Madrid, se había labrado desde el final del reinado de Felipe II, consolidándose como el lugar donde se negociaban las provisiones de dinero más importantes de la Monarquía ${ }^{10}$. Las características propias de la negociación con la Monarquía obligaron a muchos de estos financieros a instalarse en la capital de España, diseñando la estructura de sus empresas y su conexión con otras plazas, en función de esa necesidad.

La importancia de Madrid en las finanzas internacionales y en la estrategia de las empresas bancarias genovesas, se pone de manifiesto desde el momento en que la capital fue siempre la plaza de destino de los agentes genoveses y nunca su lugar de origen. En Madrid se culminaba una carrera de negocios que, a veces, se había emprendido en otra ciudad. El resto de plazas, a excepción de Génova, por ser la metrópoli, eran lugares de adiestramiento, donde se adquirían conocimientos y se alcanzaba experiencia.

Existen muchos ejemplos. Ambrosio Salvago, dejó Lisboa, donde trabajó para «Esteban Lercaro y Julio Spinola» en la década de 1610, para ocuparse de las cuentas y negocios de Octavio Centurión en Madrid, e incluso le sustituyó al frente de su casa y de la diputación del Medio General de 1608, mientras Octavio estuvo en Génova durante un tiempo ${ }^{11}$.

Antonio Balbi dejó Roma y su carrera eclesiástica para instalarse en Madrid, sustituyendo a su hermano Nicolo, que había muerto en $1620^{12}$. El propio Nicolo, que tenía una compañía en Amberes, había abandonado aquella ciudad en 1601 para venir a Madrid, donde las perspectivas de negocio eran

9 AHPNM, Protocolo 1889, f. 1246. Poder, 27/06/1622.

10 Esteban Estringana, A. Guerra y Finanzas en los Países Bajos Católicos. Madrid, 2002, pp. 49-50. Muestra los intentos del Consejo de Hacienda por centralizar la negociación de asientos en Madrid y sus intentos para acabar con las negociaciones de Flandes.

11 AHPNM, Protocolo 5455, f. 535. Poder, 7/5/1622.

12 Grendi, E. I Balbi, Torino, 1997, p. 135. 
mucho mejores según él mismo confesaba ${ }^{13}$. En su aventura invitó a sumarse a otros compatriotas suyos, preocupados por la situación que atravesaba por entonces la actividad en los Países Bajos.

En la península Ibérica, el poder de atracción de Madrid también se dejó sentir sobre otras ciudades. Además del traslado desde Valladolid de todos los financieros que habían seguido a la Corte, Juan Lucas Palavesin, inicialmente establecido en Toledo y correspondiente allí de muchos genoveses, abandonó esa ciudad para establecerse en la capital en torno a $1609^{14}$. Octavio María Cavana llegó desde Cuenca y colaboró con Nicolo Balbi. Tras la muerte de éste, le sustituyó entre los diputados del Medio General de 1608 a iniciativa de la Corona ${ }^{15}$. Francesco María Piquinoti inició sus actividades en Sevilla junto a otro genovés, Juan Esteban de la Torre, y después se trasladó a Madrid. Años después enfermó y su hermano Andrea Piquinoti, dejó Amberes para ocupar su puesto $^{16}$. De la misma ciudad provenía Francisco Serra ${ }^{17}$, quien en 1602 aún trabajaba allí como correspondiente, entre otras de la compañía de Madrid «Juan Jacome y Domingo Doria».

\section{CARACTERÍSTICAS DE LAS COMPAÑíAS GENOVESAS EN MADRID}

Aunque existieron diferencias, sobre todo en la estrategia de sus negocios y en la envergadura de sus operaciones, la organización de sus empresas tuvo rasgos comunes. La gestión de rentas e inversiones de particulares, normalmente de otros genoveses, fue una de sus principales actividades. En Génova se demandaban intermediarios capaces de cobrar los rendimientos de las inversiones que muchos habían realizado en la península Ibérica y de realizar transferencias a Italia. La actividad comercial y la exportación también concentró gran parte de los esfuerzos iniciales que realizaron todas estas compañías.

Por ejemplo, Juan Lucas Palavesin empezó a trabajar en Toledo comerciando con lana ${ }^{18}$. Bartolomé Spinola intervino en el mercado nacional de azúcar y en la exportación de lana ${ }^{19}$. Los hermanos Balbi estuvieron vinculados al comercio de terciopelo y seda entre Flandes y Sicilia, y de lana entre Alicante y Venecia. Más adelante, sus conexiones en Venecia les permitieron hacerse con la exportación de mercurio desde Idria (Eslovenia) a Sevilla, firmando contratos de provisión con la Corona, para quien Almadén resultaba insuficiente ${ }^{20}$.

\footnotetext{
13 Ibid., pp. 57-58

14 AHPNM, Protocolo 1365. Poder, 12/1601

is AHPNM , Protocolo 5457. Poder, 11/2/1623.

6 SANZ AYÁn: Los banqueros de Carlos II, p. 176. Sobre la actividad de Andrea Piquinoti. ÁLVAREZ NOGAL: El crédito de la Monarquía Hispánica, pp. 317-322.

7 AHPNM, Protocolo 1365. Escritura, 8/1602. GRENDI: I Balbi, p. 57.

1 Álvarez Nogal: Los banqueros de Felipe IV, p. 67.

19 AHPNM , Protocolo 4504, f. 175. Carta de pago, 5/1617.

20 Álvarez NogAL: Los banqueros de Felipe IV, p. 79. Grendi: I Balbi, pp. 92-115.
}

Hispania, LXV/1, núm. 219 (2005) 67-90 
Otro rasgo común a todas estas compañías es que ninguna de ellas actuó en solitario. Todas tenían fuertes apoyos económicos y sociales, indispensables para obtener la información que exigían sus negocios. Aunque su red de colaboradores abarcaba las principales plazas europeas (Amberes, Lisboa, Milán, Nápoles, Sevilla, etc.), su principal contacto se encontraba siempre en Génova. Esa compañía se encargaba básicamente de proporcionarles crédito y gestionar todas sus operaciones con las ferias italianas, a las que recurrían constantemente. Como intermediarios, los banqueros prestaban el dinero de otros, y ese dinero se encontraba y negociaba en las ferias italianas. Las ferias servían de mercado de dinero y plaza de cambio, elementos imprescindibles para poder atender los asientos y factorías. Su principal contacto en Génova también gestionaba la venta del metal precioso que enviaban a Italia desde España.

Ningún banquero genovés de Madrid habría podido firmar asientos con la Corona, sin la ayuda y colaboración de esas compañías de Génova. El propio Juan Lucas Palavesin reconocía en su testamento que le habría resultado imposible acometer los negocios en que había participado «si Juan Benito Spinola, mi hierno, no hubiera puesto el hombro en Génova y en las ferias con su crédito y hacienda propia, y de sus parientes y amigos, continuando los débitos sobre dichas ferias» ${ }^{21}$. Pero lo mismo debe aplicarse al caso de Bartolomé Spinola, Octavio Centurión, Carlos Strata, Antonio Balbi y Lelio Imbrea.

\section{COMPAÑÍAS COLABORADORAS EN GÉNOVA}

\begin{tabular}{|l|l|}
\hline MADRID & GÉNOVA \\
\hline Carlos Strata & «Francisco Perinis, Carlos Strata y Bartolomé Garbarino» \\
\hline Juan Lucas Palavesin & $\begin{array}{l}\text { Gio Francesco Pallavicino } \\
\text { Juan Benito Spinola }\end{array}$ \\
\hline Octavio Centurión & $\begin{array}{l}\text { «Filippo Cattaneo, Adam e Vicenzo Centurioni» } \\
\text { «Felipe, Adan y Juan Xacome Centurión» }\end{array}$ \\
\hline Bartolomé Spinola & «Juan Lucas y Gregorio Spinola» \\
\hline Antonio Balbi & «Stefano, Antonio e Bartolomeo Balbi» \\
\hline Lelio Imbrea & «Lelio, Juan Baptista y Juan Esteban Imbrea». \\
\hline
\end{tabular}

Los banqueros de Madrid eran los interlocutores de la Real Hacienda y los que decidían cómo se llevaba a cabo una provisión, mientras sus colaboradores de Génova ejecutaban la mayor parte de las transferencias a Europa y respaldaban con su reputación en los mercados internacionales de dinero, todas las acciones del banquero de Madrid.

21 AHPNM, Protocolo 3704. f. 328. Testamento, 16/3/1642.

Hispania, LXV/1, núm. 219 (2005) 67-90 
El acceso a las ferias italianas era una de las mayores limitaciones que presentaban los financieros portugueses. Su capacidad se concentraba en los Países Bajos, donde estaba la mayor parte de sus contactos personales. Al margen de esos contactos, les era difícil realizar transferencias u obtener crédito. En varias ocasiones, los portugueses tuvieron que acudir también a los banqueros genoveses cuando se comprometieron a realizar provisiones en el norte de Italia o Alemania. Bartolomé Spinola, como Factor General, fue el encargado de canalizar su dinero desde donde eran capaces de suministrarlo a los lugares donde lo necesitaba el Consejo de Hacienda. Para esas operaciones contó con su principal aliado en Génova, la compañía de su hermano, "Juan Lucas y Gregorio Spinola».

Los banqueros genoveses de Madrid, a pesar de ser competidores, mostraron una gran capacidad de colaboración. Este aspecto merece un estudio mucho más detenido si queremos entender el funcionamiento de las instituciones económicas en la Edad Moderna ${ }^{22}$. La cooperación era compatible con la rivalidad. Cada uno de los banqueros genoveses tenía sus propios objetivos y su propia red de colaboradores, y defendían sus intereses y los de sus socios ${ }^{23}$. Su estrategia personal chocaba muchas veces con la de otros banqueros. Todos trataban de lograr de la Corona el mejor contrato de asiento, en las mejores condiciones, y recibir por ello las mercedes, compensaciones y reconocimientos de mejor calidad posible. Sin embargo, junto a esa competitividad, existen muchos indicios de su permanente colaboración. A veces tan estrecha, que parecen actuar coordinados y como un único agente frente a la Monarquía. Al menos, así lo sentían los oficiales reales y los miembros del gobierno que negociaban con ellos. Esa capacidad para competir y colaborar forma parte de su éxito, frente a otros grupos.

La colaboración mutua se concretó de diversas formas. Por ejemplo, algunas negociaciones con el rey se llevaron a cabo de forma conjunta. En esos casos, una diputación velaba por los intereses de todos los partícipes. Octavio Centurión fue uno de los más activos, y junto a Carlos Strata y Vicencio Squarzafigo estuvo al frente de varias iniciativas de este tipo en 1625 y 1627 . Además, Octavio fue uno de los diputados del Medio General de $1608^{24}$. Los propios Medios Generales después de cada bancarrota eran iniciativas para fortalecer su posición frente a una Monarquía que hacía valer la suya suspendiendo pagos.

Su colaboración también se extendió a contratos de crédito negociados inicialmente de forma individual, pero que después de la firma, se cedían a otros.

22 GRENDI: I Balbi, p. 138. «Gli asientisti si muovono sempre piú come un grupo solidale (le "otto case») che non necesita di alter forme di legittimazione».

23 El estudio de los mecanismos institucionales que hicieron posible dicha cooperación, en especial aquellos que generaban confianza en la firma de contratos y facilitaban la actuación coordinada entre agentes competidores, resulta esencial para entender cómo funcionaban estas empresas financieras. Todo ello está en relación con la forma de organizar sus negocios.

24 AHPNM, Protocolo 5458, fol. 776. Poder, 19/12/1623. 
La negociación de un asiento corría a cargo de un hombre de negocios, pero su ejecución podían llevarla a cabo otros banqueros que, por las razones que fuesen, no querían negociar directamente con la Corona. Esto viene a demostrar el permanente contacto y colaboración entre distintas compañías genovesas, sin perder por ello su propia independencia.

Esa cesión podía llevarse a cabo de forma completa. Por ejemplo, en 1616, Octavio Centurión negoció un asiento con la Corona de 200.000 escudos en Milán y Alemania. Al final, después de haberlo firmado se lo traspasó por completo a Carlos Strata. Éste, una vez aceptado, lo traspasó con un nuevo contrato privado a otras dos compañías. Una cuarta parte a "Juan Lucas y Gregorio Spinola», y el resto a la compañía que habitualmente trabajaba para él en Génova y de la que era socio: «Francisco Perinis, Carlos Strata y Bartolomé Garbarino»25. Otro ejemplo fue el asiento de Carlos Strata en 1636, por valor de 2.150.000 escudos y ducados. Carlos cedió una quinta parte a Giulio Pallavicino, Francesco Spinola, Luca Giustiniani, Gio Benedeto Spinola y Paolo Gerolamo Pallavicino. Todos ellos residentes en Génova ${ }^{26}$.

A veces, la cesión era parcial, a través de participaciones. El que lo había firmado seguía encargándose de una parte de la provisión. Juan Lucas Palavesin se desprendió de parte de un asiento de 1.243.333,3 escudos y ducados firmado en $1616^{27}$. En este caso, sus otros partícipes fueron Adan Centurión, que lo aceptó a través de su hermano Octavio, Nicolo Balbi y Baptista Serra. Cada uno se hizo cargo de una cuarta parte del importe total, incluido el propio Juan Lucas.

La cesión de participaciones en asientos obedecía normalmente, aunque no era necesario, a una colaboración más permanente entre dos banqueros o compañías de negocios. Una alianza de este tipo existió entre Octavio Centurión y dos representantes de la familia Serra ${ }^{28}$. Octavio cedió una cuarta parte de muchos de sus asientos a Baptista Serra, y otra a Cataneo Serra, entre 1602 y 1615. Ambos residieron en Madrid, o lo hicieron durante algún tiempo. De hecho, Baptista llegó a ser embajador ordinario de la República ante el rey de España.

Octavio y sus hermanos tuvieron también una relación especial con Felipe Cataneo y con una de las ramas más destacadas del apellido Doria. Octavio estaba casado con Battina Doria ${ }^{29}$, con quien tuvo una hija, doña Clara Centurión y Doria. Una de sus hermanas, Jerónima, era la mujer de Ambrosio Doria, dux de la República ${ }^{30}$. Octavio trató de prolongar la relación con esta familia

\footnotetext{
25 AHPNM, Protocolo 1381. Escritura de obligación y cesión, 28/7/1616.

26 ÁlVAREZ NOGAL: Los banqueros de Felipe IV, p. 65.

27 AHPNM, Protocolo 1381. Escritura de obligación y cesión, 13/5/1616. Asiento, $18 / 2 / 1616$

28 AHPNM, Protocolo 1901, f. 2001. Escritura, 05/10/1628.

29 AHPNM, Protocolo 8215, f. 310. Testamento, 22/5/1652.

30 AHPNM, Protocolo 5331, f. 476. Poder, 31/5/1641. Su hermana le dio poder para llevar todos sus asuntos y rentas en España.

Hispania, LXV/1, núm. 219 (2005) 67-90
} 
concertando la boda de su nieta Ana con Andrea Doria, príncipe de Melplita ${ }^{31}$, pero desgraciadamente la niña murió antes de que el matrimonio llegara a celebrarse. Sus estrechos vínculos familiares con los Doria, podrían explicar por qué Octavio Centurión gestionaba parte de las rentas y juros que esa familia tenía en España, aunque los beneficios que reportaba esa gestión en la cuenta de resultados de la compañía no justifican por sí solos este tipo de alianzas, ni que éstas se mantuviesen en el tiempo.

Los matrimonios formaban una parte esencial de la estrategia del negocio, aunque entre los genoveses la familia no era ni el único, ni el más importante de los mecanismos institucionales sobre los que se apoyaba su estrategia comercial y financiera. Existen excepciones a la endogamia genovesa, incluso entre los grandes banqueros del rey, lo que demuestra que el matrimonio era un instrumento útil, pero no una condición imprescindible para tener éxito. Precisamente, cuatro de los banqueros que llegaron a convertirse en grandes asentistas de Felipe IV, después de una larga trayectoria comercial en España, se casaron con españolas, y no precisamente pertenecientes a la nobleza ${ }^{32}$. Salvo estas excepciones, la tendencia habitual estuvo claramente marcada por los enlaces dentro de la propia comunidad genovesa, siendo el yerno un hombre de negocios.

La familia solía estar presente en aquellos ámbitos de la empresa en los que era muy difícil redactar en un contrato las obligaciones que asumía cada una de las partes. Normalmente, se recurría a familiares cuando la confianza o reputación se consideraba más importante que las cualidades profesionales del colaborador. La política matrimonial que diseñaron algunos banqueros de Madrid, buscaba fortalecer lazos con Génova, aunque también plantearon estrategias similares dentro de la propia comunidad genovesa en Madrid. Es el caso ya citado de Julio Spinola, que casó a dos hijas con banqueros genoveses que se habían establecido en la Corte, pero que a su vez, estaban muy bien relacionados en Génova. Uno de los mejores ejemplos es el de Lelio Imbrea, que casó a sus cuatro hijas con representantes de las casas de negocios de Madrid. Antonia casó con Alejandro Palavesin, un importante asentista del rey, pariente de Juan Lucas Palavesin; Maddalena fue la esposa de Gio Francesco Balbi, que sucedió

31 Octavio Centurión dio poder a Claretina Cataneo, mujer de Adan Centurión (abuela de Ana por parte de su padre) y a Marco Antonio Doria, ambos en Génova, para discutir y ajustar las condiciones que hiciesen posible la boda de Ana con Andrea Doria. AHPNM, Protocolo 5392, f. 396. Septiembre, 1650.

32 Juan Lucas Palavesín casó con Francisca de Rojas. AHPNM, Protocolo 3704, f. 328 . Testamento, 16/3/1642. Su testimonio sobre su propio matrimonio resulta significativo: «Declaro que al tiempo que me casé con la dicha doña Francisca de Rojas, mi mujer, no se hizo escriptura de dote ni otro recaudo alguno, por quanto no reparé ni tuve atención a ningún género de hacienda, sino a solo su calidad, virtudes y buenas partes». Bartolomé Spinola se casó con María de Benavides, pero no logró tener descendencia. AHPNM, Protocolo 4530, f. 248. Liquidación, 09/06/1644. La esposa de Carlos Strata fue Agustina Spinola y Eraso, hija de Baptista Spinola y Doña Jerónima de Eraso. Baptista Spinola era un genovés asentado en Toledo en la segunda mitad del siglo XVI. AHPNM, Protocolo 3715, f. 22 y ss., 1614. Lelio Imbrea esposó a Jusepa Spinola y Eraso, hermana de Agustina, la mujer de Carlos Strata.

Hispania, LXV/1, núm. 219 (2005) 67-90 
a su tío Antonio al frente de sus negocios y de las provisiones de mercurio; Eugenia enlazó con Juan Jerónimo Spinola, uno de los hijos de Luis Spinola, otro importante banquero del rey a principios del XVII; y por último Anna, que casó con Francesco Justiniani33.

Estos lazos de sangre también explican la estrecha relación mercantil entre Juan Lucas Palavesin y Juan Benito Spinola, residente en Génova y casado con la hija del primero, María Palavesín; o la relación de Bartolomé Spinola con su sobrino Jerónimo Gentil, hijo de Julio Gentil y doña Pelegrina Spinola, hermana de Bartolomé ${ }^{34}$. Éste ofreció todo su apoyo a Jerónimo, aunque su condición de Factor General del rey le impuso ciertos límites en su colaboración. Las incompatibilidades del cargo le impedían participar en operaciones financieras de carácter privado.

Esos lazos familiares sirvieron para fortalecer la relación entre distintos agentes y compañías, pero apenas influyeron en la continuidad de las empresas después del fallecimiento de su fundador, tal y como explicaremos más adelante.

Además de los rasgos comunes que encontramos en los banqueros genoveses que se instalaron en Madrid a principios del siglo XVII, también encontramos diferencias, especialmente en sus comienzos empresariales. Esas diferencias dependían de los contactos con que contase cada uno de los hombres de negocios inicialmente; y del capital que fuese capaz de reunir para invertirlo. Tres de los banqueros más importantes de la primera mitad del reinado de Felipe IV tuvieron trayectorias distintas al iniciar su actividad.

Octavio Centurión fue el primero de su generación en negociar con la Corona, contando desde el principio con el respaldo de una gran fortuna y el apoyo de sus hermanos en Génova. Esto le permitió ofrecer desde el primer momento, millones de ducados en sus contratos de crédito, y aparecer entre los principales banqueros de la Corte de Felipe III. Por el contrario, Bartolomé Spinola inició su actividad con la Corona después de varios años ejerciendo como banquero en operaciones de gestión patrimonial y comercial, siguiendo una trayectoria similar a la de Francisco María Piquinoti y Juan Lucas Palavesin, aunque con mayor éxito en sus relaciones con la Corona. La confianza que inspiró desde sus primeras provisiones, le permitió poco a poco intervenir en operaciones cada vez más importantes y, finalmente, convertirse en Factor General del rey en $1627^{35}$. A diferencia de ellos dos, los inicios de Carlos Strata en Madrid estuvieron unidos a los de otro hombre de negocios, el famoso Ambrosio Spinola, militar y banquero. Su actividad en Flandes exigía la presencia de un activo agente en Madrid que coordinase sus provisiones de dinero. Carlos negoció con otros genoveses préstamos en Amberes para ser compensados des-

33 Álvarez Nogal: Los banqueros de Felipe IV, p. 70.

34 AHPNM, Protocolo 4527, f. 82. Testamento, 20/02/1641. Julio fue heredero de su hermano Vicencio y ambos tenían una hermana, Julia Palavesín:

35 Álvarez NoGal, C.: «El Factor General del Rey y las Finanzas de la Monarquía Hispánica», Revista de Historia Económica, $\mathrm{n}^{\circ} 17 / 3,1999$, pp. 507-539.

Hispania, LXV/1, núm. 219 (2005) 67-90 
pués con las consignaciones que ofrecía la Real Hacienda en la península Ibérica. Con el tiempo, todos estos contactos y, especialmente, su familiaridad con el funcionamiento de las finanzas reales, con su sistema fiscal y la amistad que había labrado con destacados miembros de la Corte y de los Consejos, le permitieron convertirse en banquero del rey. Sus servicios a la Monarquía fueron especialmente importantes durante la década de $1630^{36}$.

\section{Bartolomé Spinola}

Los comienzos de quien llegaría a ser el Factor General del rey entre 1627 y 1644 tuvieron dos fases muy diferentes. En la primera trabajó junto a otro genovés, Juan Andrea Spínola, con quien, a pesar de tener su apellido, no tenía ningún parentesco. Ambos fundaron una compañía: «Juan Andrea y Bartolomé Spinola» el 5 de marzo de 1611 con una duración máxima de tres años, tal y como era costumbre en la época ${ }^{37}$. Su éxito inicial les permitió renovarla durante otros tres años más en 1614, y así sucesivamente hasta que Juan Andrea falleció en el mes de octubre de $1620^{38}$. En la escritura de constitución se enumera el tipo de actividades que tenían previsto realizar, abarcando «cualquier calidad y género de negociación». La muerte de Juan Andrea no impidió que Bartolomé continuase con el negocio, aunque esta vez en solitario.

Bartolomé era muy joven cuando se estableció en Madrid. Su socio Juan Andrea era quien realmente tenía contactos en la ciudad. Había casado con una de las hijas de Julio Spinola, y era cuñado de Nicolo Balbi. De esta forma, a través de los lazos familiares, la compañía estaba conectada con dos importantes banqueros. Julio Spinola negociaba con la Corona desde la década de 1590 , y los Balbi, venían colaborando en los asientos al menos desde 1588 , aunque inicialmente lo habían hecho desde Flandes o como partícipes de Balbani, Gerolamo Scorza, Incola Sivori y Francisco de Maluenda ${ }^{39}$. La llegada de Nicolo a la Corte permitió a su familia intervenir directamente en las negociaciones de Madrid desde 1603. El propio Nicolo venía negociando asientos en Amberes desde $1598^{40}$. Todos estos contactos con otras empresas y familias no influyeron directamente en la trayectoria y negocios de la compañía de Bartolomé, pero lo cierto es que eran buenos apoyos a la hora de generar confianza entre sus clientes genoveses o castellanos. Bartolomé y su socio no eran unos desconocidos.

Aunque la administración de la compañía estuviese en manos de una o dos personas, que eran normalmente las que daban nombre al negocio, el capital de su constitución podía proceder de varios socios, algunos meramente capita-

\footnotetext{
36 Álvarez Nogal: El crédito de la Monarquía Hispánica, pp. 233-246.

${ }^{37}$ AHPNM, Protocolo 4305, f. 393. Poder, 04/03/1614.

38 AHPNM, Protocolo 2870, f. 510. Declaración, 19/10/1620.

39 GRENDI: I Balbi, p. 30.

${ }^{40}$ GRENDI: I Balbi, pp. 45-46.
} 
listas. Esa participación servía también para enlazar intereses con otras compañías, normalmente en Génova. Esos lazos con la metrópoli eran imprescindibles, tal y como hemos explicado antes.

En 1614, la compañía de Bartolomé cedió un 25\% a la compañía genovesa de su hermano Gregorio llamada "Juan Lucas y Gregorio Spinola» en Géno$v^{4}{ }^{41}$. A su vez, Bartolomé recibió una participación similar en la compañía de su hermano. La compañía se constituyó con una aportación inicial de sus socios, y la proporción que cada uno aportó marcó la forma de repartir después beneficios y pérdidas. Ese capital inicial no eximía a los socios de la obligación de responder de forma ilimitada con todo su patrimonio en el caso de existir deudas al finiquitarla.

La compañía se especializó inicialmente en pequeños negocios de intermediación, la mayor parte relacionados con la gestión domestica de dinero, el giro y la actividad comercial; siendo la gestión de fondos privados quizá el ámbito más importante de su incipiente actividad. En este apartado destaca la administración del patrimonio del duque de Maqueda, el marqués de Cañete y el conde de Alba de Aliste ${ }^{42}$. Bartolomé también fue depositario de la Cámara Apostólica ${ }^{43}$.

Para financiarse, la compañía de Bartolomé Spinola solicitó crédito en el mercado castellano de muy diversas formas y personas. La compañía aceptaba depósitos de particulares, a quienes pagaba después hasta un $7 \%$ de interés anual, en el mejor de los casos, por el tiempo que retenía su dinero. Con esos depósitos la compañía disponía de liquidez para negociar en las ferias de pagos o financiar otros negocios donde los beneficios llegaban fácilmente al $15 \%$ o, incluso, podían ser superiores ${ }^{44}$.

La actividad financiera de Bartolomé y su socio con la Corona empezó poco a poco, después de unos años trabajando en el ámbito de las finanzas privadas. El primer asiento en el que intervino la compañía se firmó en julio de 1615 . Se trataba de una provisión de 40.000 escudos en Milán ${ }^{45}$. Después, en febrero de 1617 se comprometieron en un asiento por valor de 611.666 escudos y ducados: 218.333 escudos se debían entregar en Flandes, 91.666 escudos en Milán y el resto en España. Dada la envergadura de este asiento, la compañía pidió ayuda a «Esteban Palavesín y Franco Spinola» de Génova, a quienes se cedió

\footnotetext{
${ }^{41}$ AHPNM, Protocolo 4507, f. 424. Poder, 14/10/1620. Así consta en la cédula de la compañía que fue firmada por los cuatro interesados. AHPNM, Protocolo 4305, f. 393. Poder, 04/03/1614.

42 AHPNM, Protocolo 4504, f. 52. 1617. AHPNM, Protocolo 4505, f. 505, Ratificación, 26/7/1618. AHPNM, Protocolo 4503, f. 344. Carta de pago, 1/03/1616.

${ }^{43}$ AHPNM, Protocolo 4509, f. 241. Escritura, 10/8/1622.

${ }^{44}$ GHILINO, S.: Un banchiere del '600: Stefano Balbi. Affari di stato e fiere dei cambi, Génova, 1996, p. 121; DORIA, G. «Consideraciones sobre las actividades de un «factor cambista» genovés al servicio de la Corona española», en OTAZU, A. (ed.): Dinero y Crédito, (siglos XVI al XIX). Madrid, 1978, p. 291.

45 AHPNM, Protocolo 4503, f. 411. 11/6/1616.
} 
una sexta parte de las provisiones en Flandes y Milán ${ }^{46}$. En noviembre firmaron otra provisión para Milán de 50.000 escudos, ofreciendo a estos mismos colaboradores una quinta parte, con las mismas condiciones y remuneración que en el primer caso. De los 17.500 escudos que se comprometieron a entregar en Génova al embajador del rey de España, Esteban y Franco se hicieron cargo de una tercera parte de dicha suma.

Otro partícipe habitual de la compañía genovesa fue su hermano Gregorio, quien recibió siempre una cuarta parte de los asientos. En 1621, Bartolomé llegó a un acuerdo con otras dos compañías, «Franco Spinola y David Imperial», y "Julio y Jorge Sanguinetos», para que aquel año le ayudasen a realizar las provisiones en el extranjero, e incrementó la participación de la compañía de su hermano. En los de 1621, cuyo valor total ascendía a 458.000 escudos y ducados, una vez descontados los porcentajes de sus socios, Bartolomé y su hermano se repartieron a partes iguales su participación. En los de 1622, por valor de 800.000 escudos y ducados, Bartolomé se hizo cargo de un $55 \%$ y su hermano del $45 \%$ restante ${ }^{47}$.

\section{Octavio Centurión}

Otro de los grandes banqueros de comienzos de siglo fue Octavio Centurión y Negro. Nació en Génova en torno a 1577, donde residían sus padres: Cristóbal Centurione y Liquineta de $\mathrm{Negro}^{48}$. Su llegada a la Corte del rey de España con 25 años (la que entonces se consideraba mayoría de edad en Génova para hacer negocios), obedecía a una estrategia diseñada por su familia para negociar asientos directamente en Madrid. De hecho, él y sus cinco hermanos, Battista, Filippo, Gio Giacomo, Vicenzo y Adamo Centurione ${ }^{49}$, junto a Felipe Cataneo, crearon en 1601 dos compañías para actuar de forma coordinada. La de Génova se llamó «Filippo Cattaneo, Adam e Vicenzo Centurioni» ${ }^{50}$ y la de Madrid «Octavio Centurión». Unos años más tarde, la compañía de Génova fue sustituida por «Felipe, Adan y Juan Xacome Centurión».

46 Escritura de participación en Madrid, 6/6/1617. En ella obligaban a la compañía genovesa a atender una parte de las letras que ellos habían entregado en Madrid. En concreto, Esteban y Franco se hicieron cargo de 36.388 escudos, 17 sueldos y 9 dinero en Flandes y 15.277 escudos, 15 sueldos y 6 dineros del de Milán.

47 AHPNM, Protocolo 5787, f. 310-316. Finiquito y liquidación de cuenta, 16/06/1626. Testigos: Juan Guaço, Diego de Orozco y Torivio de la Mora.

48 Su padre había intervenido como partícipe en asientos firmados por banqueros genoveses con Felipe II. PUlido BuENo, I.: La familia genovesa Centurión, (mercaderes, diplomáticos y bombres de armas), al servicio de España, 1380-1680. Huelva, 2004, pp. 239-297.

49 AHPNM. Protocolo 3715. 18/03/1614. PIFERRER, F.: Nobiliario de los Reinos y Señoríos de Espa$\tilde{n} a$, tomo III, Madrid, 1857. Este autor confunde a sus descendientes, indicando que Cristóbal es hijo de Octavio, cuando en realidad es su sobrino. También existen errores en la descendencia de éste.

so En España «Felipe Cataneo, Adam y Vicencio Centurión». 
Ambas operaron desde sus respectivas ciudades en las ferias de cambio respectivas. La de Génova en las de Besançon-Piacenza, y la de Madrid en las de Medina del Campo. La compañía genovesa fue constituida con 62.000 escudos de oro en oro de Italia, repartidos entre los siete accionistas: Felipe Cataneo aportaba 17.000 escudos, Adamo y Vicenzo, 9.500 cada uno, Battista 8.000 y Filipo, Gio Giacomo y Octavio 6.000 cada uno. La dirección de la compañía quedó en manos de los tres accionistas más importantes: Felipe Cattaneo, Adan y Vicenzo Centurion ${ }^{51}$. La compañía de Madrid nació con un capital similar a la de Génova: 60.000 ducados. 20.000 pertenecían a Octavio, y los otros 40.000 a Felipe Cataneo, Adan y Vicenzo Centurione. En este caso, el resto de hermanos de Octavio quedó al margen. En definitiva, Octavio era propietario de un $9,6 \%$ de la compañía genovesa y de un $33 \%$ de la madrileña ${ }^{52}$.

A diferencia de otros hombres de negocios que empezaron realizando pequeñas operaciones de crédito, Octavio Centurión y sus socios entraron directamente en los asientos de la Monarquía, ofreciendo asientos millonarios que ningún otro hombre de negocios podía igualar por entonces ${ }^{53}$. Esto no significa que no llevase a cabo operaciones en el ámbito privado, al igual que Bartolomé. La gestión del patrimonio que muchos genoveses tenían invertido en España fue una de sus principales actividades.

\section{Carlos Strata}

Carlos Strata fue uno de los hombres de negocios más importantes y cercanos a la persona del rey Felipe IV ${ }^{\varsigma 4}$. Al igual que el resto de banqueros de su generación, Carlos llegó a España siendo muy joven. Sus padres, Juan Francisco Strata y Jusepa Spinola, residían en Génovas5. Ya han sido señalados sus comienzos como agente en España de Ambrosio Spinola, marqués de los Balbases, lo que le permitió relacionarse con otros banqueros y miembros del gobierno de la Monarquía durante el reinado de Felipe III. Esa experiencia le permitió independizarse años después, y crear su propia compañía de negocios ${ }^{56}$.

51 AHPNM, Protocolo 7306, f. 52. Copia de cédula, 24/02/1601

52 AHPNM, Protocolo 3715

53 NeRI, E.: Uomini d'affari e di gobernó tra Genova e Madrid. Milano, 1989, pp. 54-55. Las actividades de Octavio Centurión merecen un estudio aparte, más detallado, para el que ya disponemos de abundante información.

54 Dominguez ORTiz: Política y Hacienda, 1983, pp. 114-16. El rey fue huésped de la casa del banquero. BRown, J. y ElliotT, J.H.: Un Palacio para el rey, Madrid, 1984, p. 211. Herrero SÁNCHEZ, M.: «Génova y el sistema imperial hispánico» en Álvarez-Ossorio, A. y García García, B. (eds.), La Monarquía de las Naciones. Patria, nación y naturaleza en la Monarquía de España, Madrid, 2004, p. 544.

55 Archivo Histórico Nacional (AHN), Ordenes Militares, Santiago, 1503.

56 MARsilio, C.: «Traslacio di Raccomandarle il Mio Vantaggio». La Corrispondenza Comérciale di Paolo Gerolamo Pallavicini in un Triennio Cruciale del XVII Secolo Genovese (1636-1638).

Hispania, LXV/1, núm. 219 (2005) 67-90 
Siguiendo la pauta ya descrita para otros genoveses, Carlos fundó una compañía de negocios en noviembre de 1615. Su nombre era «Francisco Perinis y Carlos Strata» y su objetivo era trabajar en Génova y en las ferias de Besançon-Piacenza. Además de Perinis, estableció relaciones en Génova con dos representantes de la casa Pallavicino, familia con la que siempre mantuvo una excelente relación. Primero con Gio Francisco, y después, con su hijo Paolo Gerolamo. Poco después, en abril de 1616, la compañía incorporó a un nuevo socio cambiando de nombre: «Francisco Perinis, Carlos Strata y Bartolomé Garbarino" ${ }^{77}$. La refundación suponía incluir a éste último en todos los negocios emprendidos hasta entonces ${ }^{58}$.

La relación de Carlos con su compañía genovesa fue exclusivamente de carácter capitalista. Como socio, poseía una parte del capital inicial con que se había constituido, pero Carlos jamás utilizó el nombre de esa compañía para sus negocios, ni intervino en su administración. Todas las negociaciones en Madrid se llevaron a cabo a través de su propia compañía madrileña ${ }^{59}$. Era una relación similar a la que tenían Bartolomé y su hermano Gregorio Spinola.

En la Corte española, ya durante el reinado de Felipe IV, Carlos Strata tuvo entre sus colaboradores y partícipes a Juan Lucas Palavesin y Lelio Imbrea. Con este último, además, estuvo emparentado. Sus respectivas mujeres eran hermanas, hijas de Baptista Spinola ${ }^{60}$. Esto influyó sin duda en la colaboración y confianza con que se trataron ambas compañías, prestándose dinero y apoyándose mutuamente en asientos y en la negociación con la Corona ${ }^{61}$.

Su principal correspondiente en Amberes fue la compañía «Juan Francisco y Juan Andrea Strata», que también había realizado asientos con Felipe III. En su testamento, Carlos recuerda la «comodidad y empréstito que les hice, por la satisfacción que tengo del amor y vigilancia con que los susodichos han acudi-

Manuscrito 2004, p. 6. Paolo Gerolamo Pallavicini dice de él en una de sus cartas: «L'interlocutore più asiduo è sicuramente Carlo Strata il quale, dopo essere vissuto nel regno di Filippo III all 'ombra del potentísimo generale Ambrogio Spinola, dopo un lungo apprendistato, e dopo la morte dello Spinola nell'assedio di Casale Monferrato nel 1630, si è trasformato in uno dei piu potenti banchieri di Filippo IV».

57 AHPNM, Protocolo 1381. Escritura de obligación, 28/7/1616. La compañía genovesa estuvo activa hasta que en 1639 se decidió liquidarla pocos meses antes de la propia muerte de Carlos en Madrid.

58 Bartolomé había casado con una hija de Francisco Perinis, y Carlos lo incorporó a sus operaciones como.su principal socio y colaborador en Génova. Entre los dos se encargaron de gobernar y administrar la compañía. Desde junio de 1630, una vez desaparecido Francisco, Bartolomé se hizo cargo en exclusiva de todas las operaciones de Génova.

59 AHPNM, Protocolo 4484, f. 564 y ss. Escritura, 26/5/1639.

60 Ver nota 32.

61 AHPNM, Protocolo 6844, f. 131. Carta de pago, 2/3/1640. Cuando muere Carlos, Joseph solicitó a Lelio que se encargase de efectuar los pagos de los asientos que había firmado su padre en 1639 , mientras ajustaba las cuentas pendientes de la compañía.

Hispania, LXV/1, núm. 219 (2005) 67-90 
do a los negocios» ${ }^{62}$. De hecho, Juan Andrea Strata fue testigo de su muerte en Madrid y recibió de Carlos el encargo de cobrar diversas deudas pendientes. Entre sus clientes y colaboradores, encontramos a Juan Thomas Ayrolo, Francisco Garvarino, Juan Bernardo Fugon y hermanos, Jerónimo de Franqui, Esteban de Negro, Juan Pedro Ángel, Enrique Salvago, Domingo Levanto, y Cataneo Serra. Todos ellos invirtieron distintas sumas en las operaciones de Carlos Strata y entretuvieron sus deudas de feria en feria.

\section{EL OCASO DE UNA GENERACIÓN DE BANQUEROS Y DE SUS COMPAÑÍAS}

La generación de banqueros que empezó a prestar dinero a la Corona a comienzos del siglo XVII sufrió las dos primeras suspensiones de pagos de ese periodo: 1607 y, especialmente, la de 1627 . A pesar de ello, ninguno de los banqueros se vio gravemente afectado y, excepto Vicencio Squarzafigo, todos continuaron con la firma de asientos y factorías, hasta convertirse en los banqueros más importantes del reinado de Felipe IV $^{63}$. Esto nos debe hacer reflexionar sobre el verdadero papel jugado por las llamadas «bancarrotas», no sólo en la situación económica del reino, con la que apenas tuvieron conexión, sino en la propia negociación crediticia. En dicha negociación tanto la Real Hacienda como los banqueros sacaban ventajas, por lo que la Corona no podía permitirse el lujo de utilizar las suspensiones de pagos para castigar y arriesgarse a perder a tan valiosos colaboradores.

No fueron las bancarrotas, sino la muerte entre 1639 y 1644, lo que alejó definitivamente a esta generación de banqueros y a sus compañías de la negociación crediticia con la Corona. En apenas cinco años, y en una fase muy importante y decisiva para la Monarquía española ${ }^{64}$, el Consejo de Hacienda vio como desaparecían sus más importantes aliados en los mercados internacionales de dinero.

El primero fue Carlos Strata, el 25 de mayo de 1639 . Al año siguiente murió su amigo y cuñado Lelio Imbrea. Antonio Balbi lo hizo en 1643. Bartolomé Spinola, el Factor General del rey, murió el domingo 13 de febrero de 1644 a las cinco de la tarde ${ }^{65}$, y el 15 de junio de ese mismo año falleció Juan Lucas Palavesin. En 1641, Francisco M. Piquinoti había enfermado mentalmente a raíz de la repentina desaparición de su cajero, quien supuestamente tenía a su cargo todos sus negocios ${ }^{66}$. En este caso, su casa de negocios encontró un sustituto en su hermano Andrea, que vino de inmediato desde Amberes. De hecho,

62 AHPNM, Protocolo 4484, f. 564 y ss. Escritura, 26/5/1639.

63 Álvarez Nogal: Los banqueros de Felipe IV, pp. 51-55 y cuadro III.1.

64 GelaberT, J.E.: Castilla convulsa (1631-1632). Madrid, 2001, pp. 172-236.

65 Archivo General de Simancas (AGS), Consejo y Juntas de Hacienda, 872. Consulta, $15 / 02 / 1644$

66 Álvarez Nogal: Los banqueros de Felipe IV, p. 74, nota 102.

Hispania, LXV/1, núm. 219 (2005) 67-90 
Andrea ya trabajaba habitualmente para él y estaba al corriente de sus operaciones de crédito. De todo el grupo, el más longevo fue, sin duda, Octavio Centurión. Curiosamente, el primero en incorporarse a los asientos de la Monarquía, fue el último en abandonarlos en $1653^{67}$.

Las consecuencias que tuvo para Castilla esta pérdida de capital humano en el sector financiero, apenas se ha tenido en cuenta a la hora de analizar las señales de debilidad que muestra la Monarquía en el contexto internacional a partir de 1640. Su impacto en la negociación crediticia pudo ser tan relevante como la creciente escasez de metales preciosos, o la hipotecada situación en la que, por entonces, se encontraban los ingresos fiscales.

Los sucesores al frente de estas casas de negocios nombrados en los testamentos, tuvieron como principal misión liquidar sus cuentas, pagar a los acreedores y litigar con la Contaduría Mayor de Cuentas para zanjar los asientos pendientes, pero ninguno de ellos pudo continuar firmando asientos como pretendía el Consejo de Hacienda.

El relevo generacional en los años cuarenta fue mucho más brusco y traumático que el producido a principios de siglo. Al iniciarse el reinado de Felipe III, los banqueros genoveses más veteranos fueron desapareciendo junto a sus empresas, siendo sustituidos casi de inmediato por otros financieros. La coyuntura política y económica era diferente. Tal y como hemos señalado, a principios de siglo muchos genoveses acudían a Madrid para establecerse, mientras que en la década de 1640, la capital de España no tenía ya el mismo atractivo.

La imposibilidad de encontrar candidatos de la categoría y capacidad crediticia de los que desaparecían, forzó a la Corona a intervenir tratando de preservar esas mismas casas de negocios, algo que ni siquiera se había planteado a principios de siglo. Esa protección, por ejemplo, hizo que la Real Hacienda fuese muy cuidadosa en la liquidación de las cuentas pendientes con los herederos de Carlos Strata, Lelio Imbrea y Francisco M. Piquinoti. Pero no sólo con los genoveses, también con algunos portugueses desaparecidos por la misma época, como Manuel de Paz, Fernando Tinoco y Diego Rodríguez de Acosta. Entre las medidas impuestas para evitar su quiebra, destaca la prohibición para embargar sus bienes ${ }^{68}$.

En el caso de los de Bartolomé Spinola, su sucesor, Jacome María, consiguió del Consejo de Hacienda el nombramiento de un juez especial para impedir que los tribunales de justicia se entrometiesen en la liquidación. Para avalar su petición, Jacome María presentó como precedente el caso de Juan Lucas Palavesin ${ }^{69}$, que no fue tampoco el único

\footnotetext{
67 AHPNM, Protocolo 8215. Escrituras, 1653.

68 Archivo General de Simancas (AGS), Consejo y Juntas de Hacienda, 872. Consulta, $15 / 02 / 1644$

69 AGS, Consejo y Juntas de Hacienda, 872. Consulta, 21/07/1644. «Pues con esto se podrá conservar la casa sin que se le agan molestias ni vejaciones por las justicias que es lo mismo que se hizo con Juan Lucas Palavesín, que también fue factor de vuestra Majestad».
}

Hispania, LXV/1, núm. 219 (2005) 67-90 
Todos estos esfuerzos para conservar la operatividad de las compañías genovesas resultaron un fracaso. Aunque se produjeron sucesiones al frente de algunas empresas, e incluso algunas negociaron nuevos créditos con la Monarquía, no fueron más que excepciones sin apenas continuidad. Prácticamente, ninguno de los herederos de los grandes banqueros del rey en el primer tercio del siglo XVII, fueron capaces de mantener en activo sus compañías. ¿Por qué?

Tal vez la forma en la que estaban organizadas estas compañías impedía su continuidad. Quizá la causa estuviese más en la enorme dependencia que estos negocios tenían de un capital humano que no podía transmitirse genéticamente. Unos conocimientos que se adquirían con una exigente práctica diaria, o unas relaciones personales en Génova que eran precisamente eso, personales y no familiares. Si culpamos a la coyuntura económica de las dificultades por las que atravesó Castilla a mediados de siglo, esto sólo nos explica la reducción en el número de asientos o su cuantía, pero no justifica la práctica desaparición de las casas que, durante años, se habían comprometido con millones de ducados. Si otras compañías, más pequeñas o menos importantes, genovesas o no genovesas, continuaron sirviendo al rey, ¿́por qué no los herederos de los grandes banqueros de principios de siglo?

La sucesión sólo parece haber tenido éxito en los casos de Nicolo-Antonio Balbi, Francisco María-Andrea Piquinoti y Octavio-Domingo Centurión. En estos tres casos, no se trataba realmente de sucesiones generacionales, sino del relevo de un empresario por otro bien experimentado. Con independencia de los vínculos familiares con el desaparecido, lo que determinó el éxito de esos relevos y la continuidad de las compañías, fue la probada experiencia de los sustitutos en los negocios, o el respaldo incondicional recibido por sus colaboradores más cercanos, especialmente en Génova.

Andrea Piquinoti sustituyó a su hermano Francisco María en 1641, dejando su compañía de Amberes y haciéndose cargo de los negocios de la de Madrid. Al final de la década se convirtió en Factor General del rey y miembro del Consejo de Hacienda. En el caso de los Balbi, la muerte de Nicolò en 1620 en Madrid fue reparada de inmediato por Antonio, que entonces se encontraba en Roma. La estructura de esta empresa, sus contactos, correspondientes y reputación se mantuvo prácticamente intacta porque quien había dado origen a la compañía no había sido sólo Nicolo, sino la voluntad de tres hermanos y una extensa familia, interesada en desarrollar sus negocios en el ámbito europeo ${ }^{70}$. Esta compañía no sólo participó en operaciones financieras. La importación de mercurio desde Idria para embarcarlo con destino a América, fue una rama esencial de su actividad. Cuando Antonio llegó a Madrid no tuvo que empezar de cero, simplemente continuar las operaciones que hasta entonces había realizado Nicolo durante veinte años, y obedecer las directrices que le llegaban de Génova. Esa fortaleza en la mutua relación de las compañías Balbi explica su

70 GRENDI: I Balbi, pp. 30-44. 
continuidad, no sólo cuando murió Nicolo, sino también al desaparecer Antonio en 1643. El puesto de Madrid fue ocupado primero por su sobrino Gio Francesco Balbi, hijo de Nicolo, y en 1650, por su primo Bartolomé ${ }^{71}$.

En el caso de Octavio Centurión, sin descendencia masculina, su sucesor fue su sobrino y yerno Domingo (hijo de Adan), quien llevaba más de 20 años trabajando en Madrid ${ }^{72}$. Domingo tenía su propia compañía y, desde sus inicios, había colaborado con su tío. Más que una sustitución en la misma casa de negocios, lo que se produjo fue una intervención más directa de la compañía de Domingo en los negocios que habitualmente tenía encomendados Octavio.

En el resto de las sucesiones, la mayoría de los herederos fueron hijos o parientes ajenos a la frenética actividad que desarrollaban diariamente los banqueros desaparecidos. Por más que hubiese voluntad y se contase con la cooperación de la Real Hacienda, era muy difícil que volviesen a encargarse de provisiones de importancia. La casa de negocios de Carlos Strata fue heredada por su hijo Joseph, español de nacimiento. A pesar de contar con el apoyo y la insistencia de la Corona para finiquitar sin sobresaltos las cuentas de su padre, apenas volvió a firmar asientos unos años después ${ }^{73}$.

Lelio Imbrea dejó todos sus negocios en manos de su hermano Juan Esteban Imbrea, que vino expresamente desde Génova para hacerse cargo de ellos ${ }^{74}$. Juan Esteban prorrogó la compañía en junio de 1641 por otros tres años más, otorgando poderes a su otro hermano, Juan Bautista, que era quien le apoyaba en Génova en sus operaciones ${ }^{75}$. Sin embargo, a pesar de que Juan Esteban fue nombrado Factor General del rey, al morir Bartolomé Spinola, y de que se le concedió el título de conde de Yebes y fue excluido de la bancarrota de $1647^{76}$, su casa de negocios dejó de servir con asientos al rey, defraudando completamente las esperanzas que había puesto en ella el Consejo de Hacienda.

Tobías y Juan Jerónimo Palavesin sucedieron a su padre Juan Lucas Palavesin. Juan Jerónimo tenía establecida su residencia en Génova y simplemente se desplazó a Madrid para liquidar las cuentas de su padre junto a su hermano ${ }^{77}$. Ninguno de los dos continuó con las actividades financieras de su padre. Juan Lucas nunca permitió a su hijo Tobías dedicarse a los negocios, a pesar de ser el primogénito y de su insistencia por asumir responsabilidades. La causa parece haber sido la preocupación de Juan Lucas por el delicado estado de salud que siempre tuvo Tobías. Lo cual nos obliga a considerar que en la vida diaria de un hombre de negocios del siglo XVII, las preocupaciones y sobresaltos podían llegar a ser tan altos como el rendimiento de algunas de sus operaciones.

71 Su muerte en 1650-51 obligó a la Real Hacienda a nombrar a un juez conservador, Antonio de Valdés, para finiquitar sus cuentas. Álvarez NOGAL: Los banqueros de Felipe IV, p. 85.

72 AHPNM, Protocolo 8215, f. 327. Codicilo, 4/4/1653.

73 SANZ AYAN: Los banqueros de Carlos $I I$, p. 184 y tabla X.

74 AHPNM, Protocolo 6844, f. 438. Poder, 25/9/1640.

75 AHPNM, Protocolo 6845, f. 174. Poder, 4/6/1641.

76 Ruiz Martín, F.: Las Finanzas de la Monarquía Hispánica, p. 133-134.

77 AHPNM, Protocolo 3704, f. 328. Testamento, 16/3/1642.

Hispania, LXV/1, núm. 219 (2005) 67-90 
Bartolomé Spinola no tuvo descendencia y fue sustituido inicialmente por su sobrino Pablo Spinola, hijo de su hermano Gregorio ${ }^{78}$, que residía en Génova. Como Pablo fue también el heredero de la compañía que su padre había fundado allí junto a su socio Juan Lucas Spinola, la compañía de Madrid pasó a manos de Jacome María Spinola, uno de los hijos de Juan Lucas, que estaba casado con una hermana de Pablo ${ }^{79}$. Jacome María también heredó el título de conde de Pezuela de las Torres y realizó algunos servicios a la Corona, pero no volvió a entrar en grandes asientos.

\section{CONCLUSIONES}

Un elemento esencial de la estructura financiera de Castilla fueron los banqueros privados. Su actividad tuvo una doble vertiente: el ámbito privado y las oportunidades de negocio que les brindaba la Corona española. La desaparición a principios de siglo de los llamados bancos de Corte, reforzó la posición de esas compañías, entre las que destacaron especialmente las genovesas. Durante toda la primera mitad del siglo XVII su presencia en las finanzas de la Monarquía fue muy importante, y a pesar de la entrada en juego de otros grupos, los genoveses nunca fueron realmente desplazados.

Entre 1600 y 1640 destacó especialmente una generación de banqueros genoveses. Ninguno de ellos acabó en la bancarrota, a pesar de que muchos sufrieron dos suspensiones de pagos decretadas por el Consejo de Hacienda, en 1607 y 1627. El crédito y la reputación de la mayoría de estas compañías no sólo resistieron los momentos de crisis, sino que con los años, crecieron y se consolidaron.

Existen características comunes a todas estas compañías, tanto en su nacimiento como en su desaparición, que revelan algunas de las claves de su funcionamiento y, en parte, de su éxito. Esta generación de banqueros había nacido en Génova, donde residía la mayor parte de sus familiares, y a donde con frecuencia se trasladaban sus hijos para casarse o residir. Génova era el lugar de origen y con Génova mantenían una necesaria y permanente conexión, social y económica.

Al llegar a la península Ibérica, la mayoría de estos hombres de negocios fundó compañías en alguna de las principales ciudades castellanas para desarrollar actividades comerciales y de procuraduría. Con el tiempo, todos acabaron asentándose en la Corte, aunque algunos lo habían hecho desde el principio. Allí consolidaron sus negocios y sustituyeron poco a poco a otros genoveses en la negociación con la Corona española. Ese era el principal objetivo de todas ellas. Su

78 AHPNM, Protocolo 4530, f. 79. Testamento, 14/02/1644.

79 AGS, Consejo y Juntas de Hacienda, 851. Billete, 8/09/1643. Jácome María Spinola había obtenido un hábito de la orden de Santiago en abril de 1642. AHPNM, Protocolo 8623, f. 31. Jácome María contrató un abogado con un salario anual de $50.000 \mathrm{mrs}$ de plata para atender todos los pleitos relacionados con la casa y negocios de Bartolomé Spinola. Esos pleitos acabaron tres años después, en julio de 1647.

Hispania, LXV/1, núm. 219 (2005) 67-90 
presencia en la Corte y en los asientos del rey les daba acceso a gruesas cantidades de metal precioso recaudado anualmente por el sistema fiscal castellano y, entre ellos, a los tesoros americanos. Se trataba, en todos los casos, de nuevos agentes que, salvo raras excepciones, no llegaban para suceder a nadie al frente de un negocio, sino para crear nuevas compañías independientes y muy competitivas, perfectamente conectadas con otras plazas europeas, pero especialmente con Génova y sus ferias. Ese es precisamente uno de los rasgos más importantes de las compañías genovesas en Madrid. Sin ese contacto con Génova, la ejecución de los asientos hubiera sido prácticamente imposible. Al menos, en cuanto a la cuantía de los créditos y a la continuidad con que los concedieron.

Los banqueros utilizaron lazos de parentesco para fortalecer sus vínculos con las compañías de Génova. A lo que se unía de forma habitual la cesión mutua de un porcentaje en el capital con el que se constituían. Esto incrementaba los incentivos económicos para colaborar más estrechamente, y permitía una mejor coordinación entre las operaciones de Génova y Madrid por los intereses económicos que recibían ambas partes.

El estudio de las casas bancarias más importantes del reinado de Felipe III y de la primera mitad del de Felipe IV ha demostrado que, a pesar de que con frecuencia los apellidos se repiten, no siempre se trataba de la misma familia o del mismo negocio. Nadie puede negar el carácter familiar de este tipo de empresas. Sin embargo, paradójicamente, salvo excepciones, la familia apenas jugó un papel importante a la hora de su continuidad. Un financiero era difícilmente reemplazable, ni siquiera buscando entre sus herederos. Las empresas financieras nacían y desaparecían unidas a las personas que las habían fundado y hecho crecer. Por supuesto, la riqueza acumulada durante años no desaparecía con su fundador, pero el dinero no era la clave en el funcionamiento de este tipo de empresas. Los genoveses no dominaron las finanzas de la Monarquía española sólo por su riqueza, sino por ser capaces de desarrollar instituciones económicas que generaban confianza y ofrecían servicios financieros a precios competitivos, tanto a la Monarquía, como a un amplio sector de la sociedad. Con independencia de las dificultades: diferentes unidades políticas, monarcas y gobernantes absolutos, una fuerte carencia de derechos civiles, diferentes idiomas, monedas, reglamentaciones comerciales, una dificultosa transmisión de información, y un largo etcétera de obstáculos, los genoveses fueron capaces de crear empresas capaces de superar esos problemas y operar en el mundo de las finanzas. El capital humano y otros aspectos relacionados, directamente o indirectamente con él, eran elementos fundamentales a la hora de constituir una compañía y darle continuidad. Por encima de la liquidez de la compañía, estaba su capacidad para generar confianza y reputación entre sus correspondientes y clientes.

La realidad es que la muerte de un gran banquero suponía la desaparición de su casa de negocios y, en la mayor parte de los casos, la paralización casi inmediata de su actividad. Lo que sí parece demostrarse es que el número de candidatos para sustituir a sus compatriotas a mediados del siglo XVII era in-

Hispania, LXV/1, núm. 219 (2005) 67-90 
ferior, en número y en capacidad operativa, a la generación que había tomado las riendas del sistema financiero a principios de siglo. Muy posiblemente, no había tantos genoveses deseosos de establecerse a Madrid en 1640, como los había habido en 1600. Otras plazas europeas empezaban a ser más atractivas que la capital de España para establecer compañías financieras.

La bancarrota decretada en 1627 no fue la responsable del debilitamiento de la colonia genovesa en Madrid. Al contrario, a partir de esa fecha, los banqueros genoveses estuvieron más involucrados en el sistema financiero de la Monarquía Hispánica. No sólo en la provisión de dinero, sino en la toma de decisiones económicas del propio Consejo de Hacienda. Los signos de debilidad y el cambio de ciclo debemos retrasarlo al menos hasta mediados del siglo XVII, cuando a la Corona le empezó a resultar más difícil encontrar banqueros para negociar su crédito, quizá porque ya no era tan buen cliente, o tal vez también porque el peso de la actividad económica se había desplazado a otros ámbitos geográficos. Los motivos parecen haber sido más de índole económica y cambios en las preferencias de los propios agentes, que por razones políticas. 